Eva Edelmann-Ohler

Sprache des Krieges 


\section{Conditio Judaica}

Studien und Quellen zur deutsch-jüdischen Literaturund Kulturgeschichte

Herausgegeben von

Hans Otto Horch

In Verbindung mit Alfred Bodenheimer, Mark H. Gelber und Jakob Hessing

\section{Band 88}




\section{Eva Edelmann-Ohler Sprache des Krieges}

Deutungen des Ersten Weltkriegs in zionistischer Publizistik und Literatur (1914-1918)

\section{DE GRUYTER OLDENBOURG}


ISBN 978-3-11-037021-8

e-ISBN 978-3-11-036597-9

e-ISBN (EPUB) 978-3-11-039556-3

ISSN 0941-5866

\section{Library of Congress Cataloging-in-Publication Data}

A CIP catalog record for this book has been applied for at the Library of Congress.

\section{Bibliografische Information der Deutschen Nationalbibliothek}

Die Deutsche Nationalbibliothek verzeichnet diese Publikation in der Deutschen Nationalbibliografie; detaillierte bibliografische Daten sind im Internet über http://dnb.dnb.de abrufbar.

(C) 2014 Walter de Gruyter GmbH, Berlin/Boston

Druck und Bindung: $\mathrm{CPI}$ books $\mathrm{GmbH}$, Leck

@ Gedruckt auf säurefreiem Papier

Printed in Germany

www.degruyter.com 